\title{
Thermal Bulk Polymerization of Cholesteryl Acrylate
}

\author{
A. C. DE VISSER, K. DE GROOT, J. FEYEN, and A. BANTJES, \\ Polymer Division, Department of Chemical Technology, \\ Twente Universily of Technology, Enschede, the Netherlands
}

\begin{abstract}
Synopsis
The thermal bulk polymerization of cholesteryl acrylate was carried out in the solid phase, the mesomorphic phase, and the liquid phase to study the effect of monomer ordering on polymerization rate and polymer properties. The rate increased with decreasing ordering (or enhanced mobility) of the monomer. Formation of inhibitive by-products during the polymerization limited conversions to $35 \%$. The sedimentation constant $S_{0}=6.2 \mathrm{~S}$ was the same for the polymers obtained in the three phases. The weightaverage molecular weight $\left(\bar{M}_{w}\right)$ was 480,000 as determined by ultracentrifugation. Poly(cholesteryl acrylate) formed in bulk is randomly coiled when dissolved in tetrahydrofuran. The thermal properties of the monomer are given.
\end{abstract}

\section{INTRODUCTION}

Liquid erystallinity, a phenomenon discovered in the last century, ${ }^{1}$ has begun to attract the attention of polymer chemists only recently. It has been demonstrated that ordering of monomer molecules induced by liquid crystallinity can have an effect on polymerization rate and properties of the prepared polymer.

To study these effects, polymerization can be carried out either in an ordered solution, or in bulk if the monomer exhibits liquid crystallinity by itself. The polymerization in liquid crystalline solution has been described by several authors. Amerik and co-workers ${ }^{2,3}$ have studied the polymerization of $p$-methacryloyloxybenzoic acid and the copolymerization of this monomer with styrene, using $p$-cetyloxybenzoic acid as a liquid crystalline solvent. They found that the ordering increased the polymerization rates. Blumstein et al.," working on similar systems, reported an increase in the isotacticity of the polymer obtained. Bulk polymerization of liquid crystalline monomers has been reported also. Paleos and Labes $^{5}$ investigated the polymerization of nematic $N$-( $p$-methoxy-ohydroxybenzylidene)-p-aminostyrene, but did not find significant effects of the ordered structure on polymerization rate or nature of the product. Amerik and Krentsel ${ }^{6}$ found that the rate of polymerization of vinyl oleate was somewhat higher in the liquid crystalline state than in the liquid and solid states. Hardy and co-workers ${ }^{7}$ polymerized cholesteryl acrylate in bulk, but it is likely from these results that polymerization took place in the solid phase rather than in the liquid crystalline phase. Toth and 1893

(c) 1971 by John Wiley \& Sons, Inc. 
Tobolsky ${ }^{8}$ described the bulk polymerization of cholesteryl acrylate and cholestanyl acrylate in the isotropic liquid phase. They found crosslinked, insoluble poly(cholesteryl acrylate) and soluble poly(cholestanyl acrylate) with a molecular weight up to $10^{4}$.

In a previous communication ${ }^{9}$ we reported the bulk polymerization of cholesteryl acrylate in the solid, liquid crystalline, and liquid states to molecular weights in the order of $10^{5}$. We wish now to report in more detail the rate of the thermal bulk polymerization of cholesteryl acrylate in its various phases and some properties of the polymers obtained.

\section{EXPERIMENTAL}

\section{Materials}

Cholesterol (U.S.P., Van Schuppen Chemie N.V.) and acryloyl chloride (Fluka 01780, containing $0.1 \%$ hydroquinone) were used without purification. All solvents used were pro analysi grade and dried by standard methods if necessary.

\section{Monomer Preparation and Characterization}

Cholesteryl acrylate was prepared in $70 \%$ yield by refluxing cholesterol and an excess amount of acryloyl chloride in benzene.

After isolation, the ester was purified by repeated crystallization from ether/ethanol. Elemental analysis yielded the following results.

AnaL. Calcd for $\mathrm{C}_{30} \mathrm{H}_{48} \mathrm{O}_{2}(440.7)$ : C, 81.76\%; $\mathrm{H}, 10.98 \% ; 0,7.26 \%$. Found: $\mathrm{C}, 81.8 \% ; \mathrm{H}, 11.0 \% ; \mathrm{O}, 7.3 \%$.

Infrared and mass spectra were consistent with the expected structure. Ebulliometry gave a number-average molecular weight of 440 . Phase transitions were determined from thermograms, obtained with a Du Pont differential thermal analyzer, by observation through a hot-stage microscope with crossed nicols and by $\mathrm{x}$-ray diffraction.

\section{Polymerization}

The bulk polymerization was studied with small samples (about $50 \mathrm{mg}$ ) to avoid temperature increase during the reaction. These portions were still large enough to be investigated by means of ultracentrifugation. The tubes in which the polymerization was carried out were cleaned by treating with concentrated nitric acid. After rinsing several times with demineralized water and with acetone, they were dried. Immediately before use, the tubes were flame-dried while being evacuated. Then about $50 \mathrm{mg}$ monomer was weighed in under nitrogen in a drybox. Each tube was flushed five times with ultrapure nitrogen, evacuated to $2 \times 10^{-2}$ $\mathrm{mm} \mathrm{Hg}$ pressure and sealed.

Polymerization was started by immersing the tube in a thermostatted oil bath and was stopped by cooling the tube in liquid nitrogen. The reaction mixture was then dissolved immediately in tetrahydrofuran. 
The contact thermometer of the thermostat bath (variability $\pm 0.01^{\circ} \mathrm{C}$ ) was calibrated to the thermometer of the hot-stage microscope to be sure that polymerization would take place in the phase chosen.

\section{Investigation of the Reaction Mixture}

The reaction mixtures were investigated by means of ultracentrifugation with a Beckman-Spinco Model E Analytical Ultracentrifuge equipped with Schlieren optics.

Sedimentation velocity runs of the dissolved samples were performed in Kel-F $12 \mathrm{~mm}$ centerpieces at 48,000 rpm. From the areas under the sedimentation peaks the amount of polymer in the reaction mixtures was calculated, the specific refractive index being determined in a BricePhoenix differential refractometer.

The results thus found, agreed within experimental error with the results obtained by fractionation. Diffusion experiments were carried out by using double-sector, capillary-type $12 \mathrm{~mm}$ Epon-filled centerpieces to measure the amount of crosslinked material. Weight-average molecular weights $\bar{M}_{w}$ of the polymers obtained by fractionation were determined by sedimentation-diffusion equilibrium, the density being determined pycnometrically.

\section{RESULTS AND DISCUSSION}

\section{Thermotropic Properties of Cholesteryl Acrylate}

The phase transitions of cholesteryl acrylate as determined by observations through a hot-stage microscope with crossed nicols $(M)$, differential thermal analysis (DTA), and x-ray diffraction (X) are presented in Table I, together with the results of other investigators. The transition at $65^{\circ} \mathrm{C}$ (D) is a reversible solid-phase transition; on heating the sample to $75^{\circ} \mathrm{C}$ an endotherm is observed. When the sample is cooled an exothermic peak occurs at the same temperature. The x-ray diffractograms at $14^{\circ} \mathrm{C}, 75^{\circ} \mathrm{C}$, and again at $14^{\circ} \mathrm{C}$ confirmed the findings by DTA. A similar transition has been reported by Barrall et al. ${ }^{10}$ for cholesteryl valerate. The transition from the solid into the enantiotropic cholesteric

TABLE I

Thermal Properties of Cholesteryl Acrylate

\begin{tabular}{|c|c|c|c|c|c|}
\hline \multirow[b]{2}{*}{ Source } & \multicolumn{5}{|c|}{ Temperature of transition, ${ }^{\circ} \mathrm{C}$, to } \\
\hline & Solid & Smectic & Cholesteric & Nematic & Isotropic \\
\hline This & $65(\mathrm{D})$ & & $121(\mathrm{D})$ & & $126(\mathrm{D})$ \\
\hline investigation & $64(X)$ & & $122.5(\mathrm{M})$ & & $125(\mathrm{M})$ \\
\hline Hardy et al. ${ }^{7}$ & & $<118.7$ & & 118.7 & 125.8 \\
\hline Toth et al. ${ }^{8}$ & & & & & 127 \\
\hline
\end{tabular}

a (D): determined by DTA in $\mathrm{N}_{2}$ atmosphere at $1^{\circ} \mathrm{C} / \mathrm{min}$ heating rate; (M): determined by microscopy; $(\mathrm{X})$ : determined by $\mathrm{x}$-ray diffraction in $\mathrm{N}_{2}$ atmosphere. 


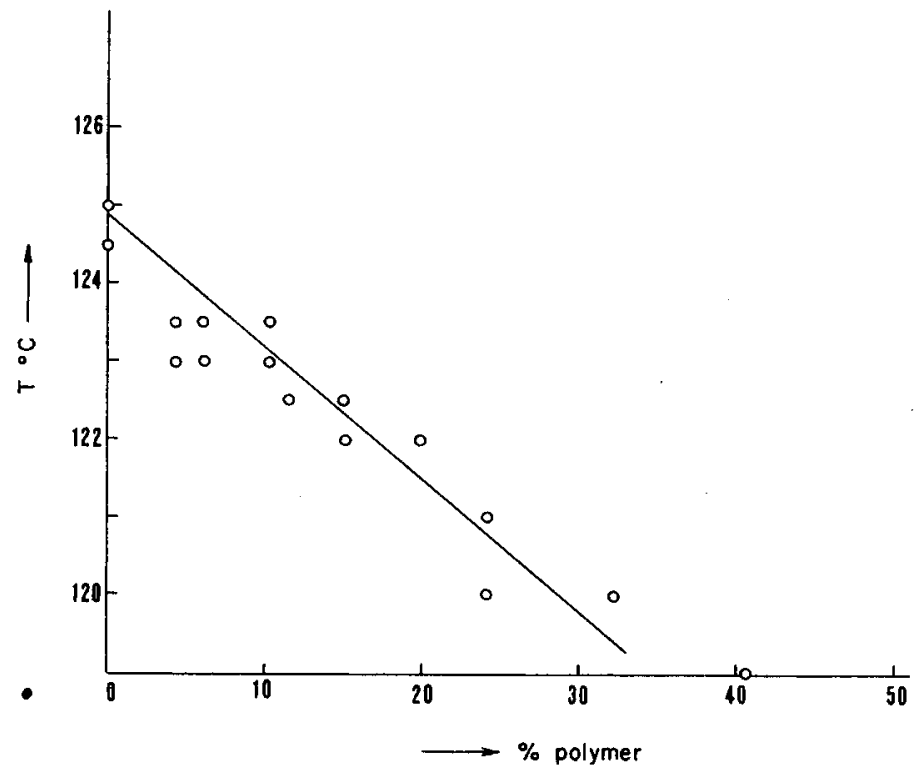

Fig. 1. Effect of the percentage polymer on the mesomorphic-isotropic transition temperature of a monomer-polymer mixture.

mesophase takes place at $122.5^{\circ} \mathrm{C}(\mathrm{M})$ and the mesomorphic-isotropic transition at $125^{\circ} \mathrm{C}(\mathrm{M})$. On cooling, the latter transition is precisely reversible, but the former is variable. Toth and Tobolsky ${ }^{8}$ observed only on cooling a cholesteric mesophase at $90^{\circ} \mathrm{C}$. Hardy and co-workers ${ }^{9}$ did not observe any phase transition between $-7^{\circ}$ and $119^{\circ} \mathrm{C}$ and concluded that cholesteryl acrylate is in the smectic state in this temperature interval. In both publications about the same temperature was reported for transition into the isotropic liquid, more or less in agreement with our observations. The temperature of the mesomorphic-isotropic transition was measured as a function of the composition of various monomerpolymer mixtures to investigate the effect of polymer formation on this transition. The results are given in Figure 1.

\section{Polymerization Kinetics}

A kinetic study of the thermal polymerization was conducted in the solid phase at $120^{\circ} \mathrm{C}$, the mesomorphic phase at $123^{\circ} \mathrm{C}$ and the isotropic phase at $126^{\circ} \mathrm{C}$. In Figure 2 the amount of polymer formed in the reaction mixture is plotted versus time.

The polymerization in the solid phase takes place at a much slower rate than in the two other phases. The rate in the mesophase becomes equal to the one in the isotropic phase after about $10 \%$ polymer has been formed. Figure 1 shows that in a monomer-polymer mixture containing ca. 10\% polymer, the transition from the liquid crystalline to the isotropic state 


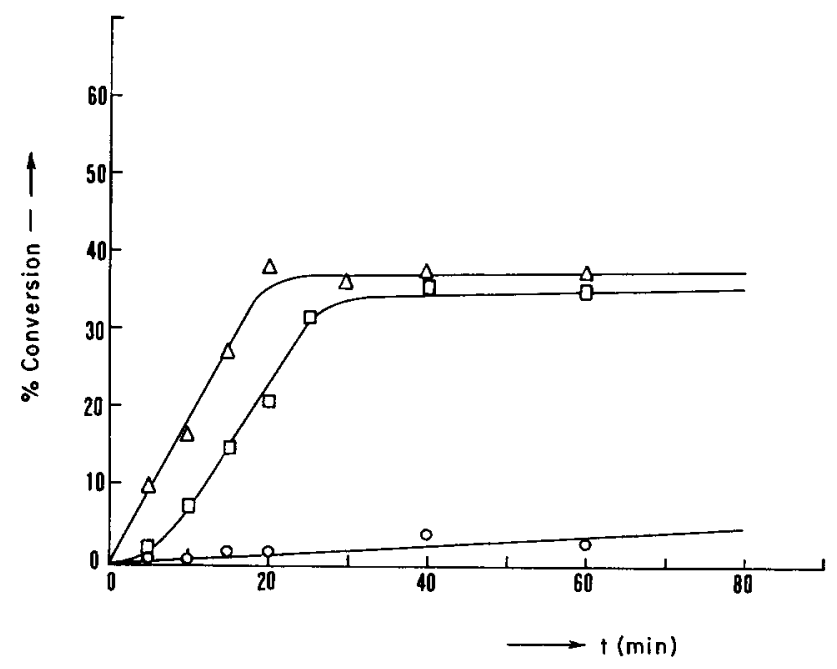

Fig. 2. Conversion-time plots for the bulk polymerization of cholesteryl acrylate: (O) in the solid phase at $120^{\circ} \mathrm{C}$; (a) in the mesomorphic phase at $123^{\circ} \mathrm{C}$; $(\Delta)$ in the liquid phase at $126^{\circ} \mathrm{C}$.

occurs at $123^{\circ} \mathrm{C}$. Thus only during the first 10 min the reaction really proceeds in the mesophase at a temperature of $123^{\circ} \mathrm{C}$. The polymerization rate increases on going from the solid via the liquid-crystalline to the liquid phase. This result shows that only the mobility, not the ordering of the monomer molecules, enhances the rate. The temperature difference between the polymerizations in the liquid and mesophase does not affect the rate, as follows from the identical slopes of the curves between 10 and 20 min. After about 20 min the reaction stops. At this point, ca. $35 \%$ polymer has been formed. Reaction times up to $70 \mathrm{hr}$ did not increase the amount of polymer. Diffusion runs with the ultracentrifuge showed that no appreciable amount of crosslinked material was present and that the reaction mixture beside the polymer only contained low molecular weight, not sedimenting material. This followed also from the numberaverage molecular weight value of 520 , measured by ebulliometry, for the material that remained in solution after the polymer had been removed from the reaction mixture by precipitation. Thin-layer chromatography showed that this material consisted mainly of monomer. Also the transition temperatures of the material were only one or two degrees lower than those of the pure monomer. However, this material did not polymerize thermally anymore in the liquid phase. This suggested that impurities formed in a side reaction inhibited the polymerization. Consequently, when the polymerization rate would be much higher than the rate of the side reaction, one would expect a considerably higher yield. This we confirmed by conducting a polymerization initiated by azobisisobutyronitrile (AIBN): the polymer yield increased to $93 \%$. (AIBN has a half-life time of about $30 \mathrm{sec}$ at $126^{\circ} \mathrm{C}$.) 
As expected, the yield of the thermal polymerization in the mesomorphic phase was lower than in the isotropic phase because of the lower initial rate of polymerization, favoring the side reaction.

Our conclusions are that the rate of thermal polymerization of cholesteryl acrylate in bulk increases with decreasing order of the monomer system and that the rather low conversions are a result of formation of inhibitive by-products during the polymerization.

\section{Solution Properties of the Polymer}

The weight-average molecular weight $\bar{M}_{w}$ of polymer from the kinetic experiments at $126^{\circ} \mathrm{C}$ was found to be 480,000 by sedimentation-diffusion equilibrium and did not change with the percentage conversion. The intrinsic sedimentation constant $[S]$, defined as

$$
[S]=S_{0} \cdot \eta /(1-\bar{v} d)
$$

[where $S_{0}$ is the sedimentation constant at zero concentration $\left(S_{0}=6.2 \mathrm{~S}\right)$; $\eta$ and $d$ are, respectively, the viscosity and density of the solvent $\left(\eta^{20}=\right.$ $0.487 \times 10^{-2}$ poise), and $\bar{v}$ is the partial specific volume of the polymer $(\bar{v}=0.95 \mathrm{cc} / \mathrm{g})]$ was calculated to be $0.195(\mathrm{~S} \times$ poise $)$ in tetrahydrofuran. The intrinsic viscosity of the polymer in this solvent is $[\eta]=0.46 \mathrm{dl} / \mathrm{g}$. Mandelkern and Flory ${ }^{11}$ have derived the following relation for random coils in solution:

$$
[S][\eta]^{1 / 3} / M^{2 / 3}=\phi^{1 / 3} p^{-1 /} N_{A}
$$

[where $\Phi^{1 / 3} p^{-1}$ is a constant, equal to $2.5 \times 10^{6}$ for homogeneous, randomly coiled polymer, and $N_{A}$ is Avogadro's number. This value may be $30-40 \%$ lower, depending on the degree of inhomogeneity, according to Gouinlock et al. ${ }^{12}$ and Hunt et al. ${ }^{13}$ The values found for $[S],[\eta]$ and $\bar{M}_{w}$ result in $\Phi^{1 / 3} p^{-1}=1.5 \times 10^{6}$, which value agrees satisfactorily with the value calculated for a heterogeneous polymer.

The sedimentation rate for the polymers obtained in the solid and mesomorphic phase was the same as the $S$ value of the polymer from the liquid phase. Therefore we conclude all three polymers to have the same average molecular weight and to be randomly coiled in tetrahydrofuran.

\section{References}

1. F. Reinitzer, Monatsh, 9, 421 (1888).

2. Yu. B. Amerik, I. I. Konstantinov, and B. A. Krentsel, in Macromolecular Chemistry Tokyo-Kyoto 1966 (J. Polym. Sci. C, 23), I. Sakurada and S. Okamura, Eds., Interscience, New York, 1968, p. 231.

3. A. A. Baturin, Yu. B. Amerik, and B. A. Krentsel, paper presented at Third International Liquid Crystal Conference, Berlin, August 24-28, 1970.

4. A. Blumstein, N. Kitagawa, and R. Blumstein; paper presented at Third International Liquid Crystal Conference, Berlin, August 24-28, 1970.

5. C. M. Paleos and M. M. Labes, paper presented at Third International Liquid Crystal Conference, Berlin, August 24-28, 1970. 
6. Yu. B. Amerik and B. A. Krentsel, in Macromolecular Chemistry, Prague 1965 (J. Polym. Sci. C, 16), O. Wichterle and B. Sedlácek, Eds., Interscience, New York, 1967, p. 1383.

7. Gy. Hardy, F. Cser, A. Kallo, K. Nyitrai, G. Bodor, and M. Lengyel, Acta Chim. Acad. Sci. Hung., 65, 287, 301 (1970).

8. W. J. Toth and A. V. Tobolsky, J. Polym. Sci. B, 8, 289 (1970).

9. A. C. de Visser, J. Feyen, K. de Groot, and A. Bantjes, J. Polym. Sci. B, 8, 805 (1970).

10. E. M. Barrall II, J. F. Johnson, and R. S. Porter in Thermal Analysis Vol. I, R. F. Schwenker and P. D. Carn, Eds., Academic Press, New York-London, 1969, pp. 556-570.

11. L. Mandelkern and P. J. Flory, J. Chem. Phys., 20, 212 (19522).

12. E. V. Gouinlock, P. J. Flory, and H. A. Scheraga, J. Polym. Sci., 16, 383 (1955).

13. M. L. Hunt, S. Newman, H. A. Scheraga, and P. J. Flory, J. Phys. Chem., 60, 1278 (1956).

Received February 17, 1971. 